\title{
Jurisdictional Competition For Quality Standards: Competition of Laxity?
}

\author{
Thomas Apolte* \\ Gerhard Mercator University \\ Department of Economics
}

\begin{abstract}
Regulatory competition arises where governments mutually accept quality standards in a common market. In a recent paper Hans-Werner Sinn claims that regulatory competition will be subject to market failure and lead to "competition of laxity" in a sense that only the lowest possible quality standards survive regulatory competition. In this paper it is shown that these results do not need to follow when some fairly restrictive assumptions of Sinn's model are relaxed. First, if his assumption of a large number of small jurisdictions is given up in favor of the assumption that a small number of larger jurisdictions compete for quality standards, then the resulting quality standards will end up above the minimum level, albeit still below an efficient level. If no subsidies are allowed in order to compensate for losses of producers working under strict quality standards, quality standards will generally converge to the level of the jurisdiction with the lowest quality preferences, but not below this level. Another assumption of Sinn is that governmental quality standards cannot better be judged by consumers than product qualities by producers. If this assumption is relaxed, regulatory competition may even be superior to a harmonized quality standard.
\end{abstract}

Keywords: Regulatory competition; Common market; Market failure

JEL classification: D82; H77

\author{
* Gerhard Mercator University \\ Department of Economics \\ D-47048 Duisburg \\ Germany
}

phone: 49-203-379-2351

fax: 49-203-378-2353

Email: Apolte@uni-duisburg.de 


\section{Jurisdictional Competition For Quality Standards: Competition of Laxity?}

Keywords: Regulatory competition; Asymmetric information; Market failure JEL classification: D82; H77

\section{Introduction}

In a recently published article, Hans-Werner Sinn (1997) argued that competition among decentralized governments generally leads to problems of market failure as long as governments are bound to the so called selection principle, i. e. only engage in activities in which the private sector fails to provide sufficient results. Sinn exemplified his thesis with three classical fields of governmental activities: first, the provision of public goods, second the enforcement of quality standards in case of lemon problems, and third governmental redistribution to the poor. In this paper, one of these aspects is critically examined, namely the thesis that an Akerlof-type failure in quality competition (see Akerlof 1970) will be replicated on the level of decentralized governments when these governments act under competitive pressure. In Sinn's view, minimum quality standards stipulated and enforced by governments (henceforth referred to as quality standards) are competed away in much the same way as high product qualities voluntarily chosen by competing producers (henceforth referred to as producers' qualities).

Competition for quality standards arises when there are two or more decentralized governments in a common market and when all governments have to obey the principle of mutual recognition. According to this principle, each government has to respect the quality standards of every other government and cannot require some additional standards to be met 
before allowing the respective goods to be imported. Hence, under the principle of mutual recognition, producers from several jurisdictions with, at least initially, several different quality standards compete on a single integrated market (see Sun/Pelkmans 1995). One of the properties of this kind of competition is that producers from different jurisdictions compete, inter alia, with quality standards that consumers may not be able to directly observe. Sinn's thesis is as follows: As long as consumers can neither directly nor indirectly observe quality of products and quality standards of governments, competition among governments will lead to competition of laxity in the sense that only the lowest possible quality standards will survive the competitive process (see Sinn 1997, pp. 264).

The rationale behind Sinn's thesis rests on two crucial assumptions. First, Sinn assumes a large number of competing governments where each government's quality standard has only a negligible influence on the average quality standard of the common market. Second, he assumes that consumers are ignorant with respect to governmental quality standards and with respect to the producer's quality to exactly the same extent. In my view, these assumptions are not very realistic, at least not under any circumstances. The EU common market is, for instance, comprised of only 15 governments, some of which are responsible for more than one fifth of the total of EU consumers. It therefore seems reasonable to assume that at least some of the governments do have a significant influence on the average quality standard in the common market. Also, it does not seem reasonable to assume that consumers are equally ignorant with respect to governmental quality standards and producers' qualities. Rather, there are good reasons to assume that detectibility of qualities and quality standards are different between governments and producers.

For these reasons, Sinn's approach is modified in this article along the lines described above. In the next section, the economic model behind competition of laxity is briefly outlined. In the 
third section the model is modified such that only the governments of two large jurisdictions compete for quality standards. In the fourth section it is assumed that there are differences in the ability of consumers to observe the producer's qualities on the one hand and governmental quality standards on the other.

\section{Regulatory competition among small jurisdictions}

Sinn's considerations start with a simple formalization of the lemons problem introduced by Akerlof. ${ }^{1}$ Differently from Akerlof, however, Sinn's formalization does not rest on a given set of consumer durables but rather on newly produced consumer goods. In the absence of governmental quality standards, producers voluntarily chose among different qualities where higher qualities imply higher production costs. The utility of a representative consumer, in turn, depends on the quantity $x$ and quality $q$ of a consumer good as well as the quantity $y$ of a numeraire good. The utility function is specified as:

$$
U(x) \cdot V(q)+y,
$$

and the budget constraint is:

$$
\bar{y}=y+P \cdot x .
$$

Since the consumer is ignorant with respect to producers' qualities he cannot choose among qualities and will thus maximize his utility according to the following first-order condition alone:

$$
U^{\prime}(x) \cdot V(q)=P
$$

\footnotetext{
${ }^{1}$ See Sinn (1997), pp. 265 - 268; see also: Akerlof (1970); Leland (1979); Wilson (1980).
} 
The producer's cost function depends on both quantity and quality of the good produced. The producer faces constant marginal costs with respect to quantity and increasing marginal costs with respect to quality:

$$
c(q) \cdot X \text { with } c^{\prime}(q) \geq 0, c^{\prime \prime}(q) \geq 0 \text {. }
$$

Quality has a certain minimum $q^{*}>0$ with $q^{\prime}\left(q^{*}\right)=0$. Since consumers are unable to observe the different qualities $q$ of the different producers, their willingness to pay generally depends on average quality $\tilde{q}$. The profit function of a representative producer is thus:

$$
P(\tilde{q}) \cdot X-c(q) \cdot X
$$

The lemons problem can now easily be demonstrated by the first-order conditions of the producer's maximization problem. The conditions are

$$
c^{\prime}(q) \cdot X=0
$$

with respect to quality and

$$
P=c(x)
$$

with respect to quantity. Since it does not pay for the producers to make any efforts to raise quality above the minimum level, his optimal quality standard is $q=q^{*}$. This is inefficiently low, which can be seen with the help of a welfare maximizing agent's objective function:

$$
\max _{q} U(x) \cdot V(q)+\bar{y}-c(q) \cdot x
$$


The first-order condition yields the optimal quality standard:

$$
U(x) \cdot V^{\prime}(q)=c(q) \cdot x .
$$

A welfare maximum requires marginal cost to be equal to marginal utility of a quality increase. In the lemons equilibrium described by equation (6), however, marginal cost of a quality increase is zero. This deficiency of quality competition in case of asymmetrical information can in many cases be cured by mechanisms of indirect quality detection, such as competition for reputation, signaling and so forth. ${ }^{2}$ It may be subject to dispute as to how many cases of definite market failure in quality competition remain. However, there will be at least some of such cases where quality can neither directly nor indirectly be observed, and where inefficiently low qualities may lead to serious problems. And for these cases alone Sinn claims his thesis of failing competition among governments to be valid (see Sinn 1997, pp. 268 -270). According to his assumption of small jurisdictions he claims that no government can effectively influence the average quality standard of the common market. Since consumers are assumed to have no preferences with respect to the jurisdiction they buy their consumer goods from, no government can influence the average quality of the consumer goods consumed by "their" inhabitants. The only way to influence welfare in the respective jurisdiction is thus to set the quality standard such that it maximizes profit of domestic producers. Each government will thus set its quality standard $q^{* *}$ such that it maximizes domestic producers' profit. The maximization problem of a welfare-maximizing decentralized government is thus:

\footnotetext{
${ }^{2}$ See Spence (1976); Shapiro (1983); Kreps/Wilson (1982); Wolinsky (1983); Allen (1984); Kihlstrom/Riordian (1984).
} 


$$
P(\tilde{q}) \cdot X-c\left(q^{* *}\right) \cdot X
$$

and the corresponding first-order condition is:

$$
c^{\prime}\left(q^{* *}\right)=c^{\prime}\left(q^{*}\right)=0
$$

A welfare-maximizing government will, under competitive pressure, set the same inefficiently low quality standard as producers under competition. Market failure will thus be replicated on the level of governments. This result, however, rests on the assumption of small governments and on the assumption of equal consumer ignorance on the level of producers and on the level of governments. In the next section, the first assumption will be given up in favor of the assumption of only two large jurisdictions.

\section{Regulatory competition among large jurisdictions}

Assume a common market consisting of two identical jurisdictions $j=1,2$. The entire amount of a produced and consumed consumption good is $\bar{X}$. Jurisdiction 1 has a market-share in the production of the consumption good of $\pi$ with $0 \leq \pi \leq 1$. Consequently, jurisdiction 2 has a market share of $1-\pi$. The average quality standard then is:

$$
\tilde{q}=\pi \cdot q_{1} * *+(1-\pi) \cdot q_{2} * *
$$

The number of producers in each jurisdiction is normalized to one. Each individual in jurisdiction 1 consumes an amount of $x_{1}$, resulting in a total consumption of $X_{1}=n \cdot x_{1}$ in this jurisdiction, where $n$ is the number of consumers which is identical in both jurisdictions. The number of consumers is assumed to be identical to the number of inhabitants in each jurisdiction. Given that $x_{2}$ is per capita consumption in jurisdiction 2, total consumption in 
the common market sums up to $\bar{X}=X_{1}+X_{2}$. Each individual in jurisdiction 1 and 2 chooses among the consumption goods from one of the two jurisdictions without regional preferences. For simplicity, however, it is assumed that each individual $i=1,2, \ldots, n$ in jurisdiction $j=1,2$ buys his consumption goods $x_{j}^{i}$ either entirely from producers in jurisdiction 1 or entirely from producers in jurisdiction 2. Hence, with the probability of $\pi$ will individual $i$ in jurisdiction $j$ buy all his consumer goods from jurisdiction 1 and thus, by chance, "catch" the quality standard $q_{1} * *$ of this jurisdiction without being able to judge its properties. Likewise, with the probability of $1-\pi$ will he buy all his consumer goods in, and thus "catch" the quality standard of, jurisdiction $2 .^{3}$

It is generally assumed that both governments act as strict welfare maximizers in a sense that they maximize utility of a representative individual in their respective jurisdiction. Like Sinn, it is assumed here that profits of domestic producers enter the governments' objective function. A reason could be that all profits are equally distributed back to the respective domestic population. They thus add to the budget $\bar{y}$ of each domestic inhabitant and enhance its consumption. The latter, however, is only true for profits gained from exports into the other jurisdiction, since profits from domestic sales first lower consumption of domestic consumers via prices above average cost and then increase the budget by exactly the same amount via the distribution of the profits to the consumers/inhabitants. If we define $\bar{y}_{i}^{d}$ as the budget stemming from domestic sources alone, then the following objective function of government 1 follows:

$$
\left.\max _{q_{1} * *} ! U_{1}\left(x_{1}\right) \cdot \mid \pi \cdot V_{1}\left(q_{1} * *\right)+(1-\pi) \cdot V_{1}\left(q_{2} * *\right)\right]+\bar{y}_{1}^{d}+P \cdot \pi \cdot x_{2}-c_{1}\left(q_{1} * *\right) \cdot \pi \cdot \bar{x}
$$

\footnotetext{
${ }^{3}$ To simplify the presentation the subscript $i$ will be suppressed in the following.
} 
Export revenues enter the government's objective function as well as consumer utility derived from consumption quantity $x_{1}$ and quality $q_{1}^{* *}$ or $q_{2}^{* *}$. Additionally, all per capita costs for the domestic production of domestically consumed goods enter the government's objective function, that is $c_{1}\left(q_{1} * *\right) \cdot \pi \cdot x_{1}=C_{1}\left(q_{1} * *\right) \cdot \pi \cdot x_{1} / n$, and exported goods, that is $c_{1}\left(q_{1} * *\right) \cdot \pi \cdot x_{2}$, which sum up to $\left.c_{1}\left(q_{1} * *\right) \cdot \pi \cdot\left(x_{1}+x_{2}\right)\right)=c_{1}\left(q_{1} * *\right) \cdot \pi \cdot \bar{x}$.

From the assumption of a common market and from the assumption that consumers cannot detect differences in the quality standards it follows that, in equilibrium, all governments and producers in the common market face identical prices. Since it was assumed that average costs are constant with respect to the amount produced there will be zero economic profits in equilibrium for the producer in the jurisdiction with the lowest quality standard. Any prices that would yield positive economic profits to this producer would be competed away since consumers cannot distinguish between goods produced under high quality standards from those produced under low quality standards. Downward pressure on prices would not stop where a zero-profit condition for producers working under high quality standards is fulfilled. It would rather continue exactly to the point where the lowest-cost producer, that is the one working under the least demanding quality standard, reaches zero economic profits.

Assume, for instance, that the lowest quality preference would be the one of the inhabitants of jurisdiction 2. Among isolated jurisdictions without regulatory competition efficient quality standards $q_{j}^{e}$ would be ordered as:

$$
q_{1}^{e}>q_{2}^{e}
$$

Arising regulatory competition will induce government 1 to reduce its quality standard below the efficient level $q_{1}^{e}$. I will show later, however, that the quality standard of jurisdiction 1 
will nevertheless remain higher than that of jurisdiction 2 under any circumstances. If we call $q_{1}^{u}$ and $q_{2}^{u}$ the equilibrium quality standards under regulatory competition, the initial order will survive, that is we will always have $q_{1}^{u}>q_{2}^{u}$. Therefore, economic profits of producers in jurisdiction 2 will just be competed to zero:

$$
P(\tilde{q}) \cdot(1-\pi) \cdot \bar{X}-c_{2}\left(q_{2} * *\right) \cdot(1-\pi) \cdot \bar{X}=0
$$

Since jurisdiction 2 will continue to be the lowest-quality jurisdiction, rearranging (15) yields the equilibrium market price of the consumption good:

$$
P=c_{2}\left(q_{2} * *\right)
$$

Inserting this price into jurisdiction one's objective function yields:

$$
\begin{aligned}
& \left.\max _{q_{1}^{* *}} ! U_{1}\left(x_{1}\right) \cdot \pi \cdot V_{1}\left(q_{1} * *\right)+(1-\pi) \cdot V_{1}\left(q_{2} * *\right)\right]+\bar{y}_{1}^{d}+c_{2}\left(q_{2} * *\right) \cdot \pi \cdot x_{2} \\
& -c_{1}\left(q_{1} * *\right) \cdot \pi \cdot \bar{x}
\end{aligned}
$$

The first-order condition with respect to the quality standard in jurisdiction 1 then is:

$$
U_{1}\left(x_{1}\right) \cdot V^{\prime}\left(q_{1}^{* *}\right)=c_{1}{ }^{\prime}\left(q_{1} * *\right) \cdot \bar{x}
$$

According to equation (9), efficiency would require the following condition to be fulfilled:

$$
U_{1}\left(x_{1}\right) \cdot V^{\prime}\left(q_{1} * *\right)=c_{1}{ }^{\prime}\left(q_{1} * *\right) \cdot x_{1}
$$

The only difference between conditions (18) and (18a) is that marginal utility from quality equals marginal cost times consumption in the common market $\bar{x}$ instead of consumption in 
jurisdiction 1 alone, that is $x_{1}$. Since $\bar{x}>x_{1}$ and given that the usual assumption of declining marginal utility holds equilibrium quality standard will be too low, that is $q_{1}^{u}<q_{1}^{e}$. This result is shown in figure 1 . Since $x_{1}$ is smaller than $\bar{x}, c_{1}{ }^{\prime}\left(q_{1} * *\right) \cdot x_{1}$ is below $c_{1}{ }^{\prime}\left(q_{1} * *\right) \cdot \bar{x}$ for any quality standard $q_{1} * *>q^{*}$. Thus, under regulatory competition, the quality standard chosen by government 1 according to condition (18) is always below its efficient level.

\section{insert figure 1 here}

\section{FiguRE 1: SUbOPTIMAL QUALITY STANDARD IN REGULATORY COMPETITION}

The reason behind this result is straightforward. Producers in "higher-quality jurisdictions" have to produce under higher costs than those in the "lowest-quality jurisdiction." To the extent of $\bar{x}-x_{1}=x_{2}$, however, high quality products are not enjoyed by the population of jurisdiction 1 but rather by the population of jurisdiction 2. Since prices of high-quality products from jurisdiction 1 are as low as those of the low-quality products from jurisdiction 2 the cost difference between high and low quality has to be born by population 1 alone. Therefore, an interregional externality arises that induces government 1 to reduce its quality standard from $q_{1}^{e}$ to $q_{1}^{u} \cdot{ }^{4}$ By contrast, since prices in the common market correspond to the low quality in jurisdiction 2, government 2 will not reduce its quality standard in regulatory competition. It will rather choose an efficient standard according to its inhabitants' quality preferences. This can easily be shown by substituting (16) into government two's objective function. The following objective function results:

\footnotetext{
4 This interregional externality is analogous to interregional fiscal externalities; see Flatters/Henderson/ Mieszkowski (1974); Zodrow/Mieszkowski (1986).
} 


$$
\max _{q_{2} * *} ! U_{2}\left(x_{2}\right) \cdot\left[\pi \cdot V_{2}\left(q_{1} * *\right)+(1-\pi) \cdot V_{2}\left(q_{2} * *\right)\right]-(1-\pi) \cdot c_{2}\left(q_{2} * *\right) \cdot x_{2} \cdot
$$

The first-order condition is:

$$
U_{2}\left(x_{2}\right) \cdot V_{2}{ }^{\prime}\left(q_{2} * *\right)=c_{2}{ }^{\prime}\left(q_{2} * *\right) \cdot x_{2} \text {. }
$$

The resulting quality standard would thus be the efficient standard $q_{2}^{e}$ according to condition (9). We can thus formulate the following proposition:

Proposition: The lowest-quality jurisdiction will chose an optimal quality standard, whereas the high-quality jurisdiction will chose a standard that is below efficiency level but still above the standard of the lowest-quality jurisdiction. It is thus always $q_{2}^{e}<q_{1}^{u}<q_{1}^{e}$ and $q_{2}^{u}=q_{2}^{e}$ in regulatory competition.

Proof: As shown, $q_{1}^{u}<q_{1}^{e}$ follows from conditions (18) and (18a). In order to proof that $q_{1}^{u}>q_{2}^{e}$ assume that government 1 would reduce its quality standard until $q_{2}^{e}=q_{1}^{u}$. Marginal cost of production in jurisdiction 1 would then be $c_{1}{ }^{\prime}\left(q_{1} * *\right)=c_{2}{ }^{\prime}\left(q_{2} * *\right)$. Any further reductions in quality to a level $q_{1}^{u u}<q_{2}^{e}$ would induce the market price to fall to $P=c_{1}\left(q_{1}^{* *}\right)<c_{2}\left(q_{2}^{e}\right)$. Jurisdiction 1 will thus export with zero profits under any quality standard equal to, or below, $q_{2}^{e}$. Hence, lowering the quality standard below $q_{2}^{e}$ would not bring any extra profits from export. Since on the other hand, corresponding to equation (9), $U_{1}\left(x_{1}\right) \cdot V^{\prime}\left(q_{1}^{u u}\right)<U_{1}\left(x_{1}\right) \cdot V^{\prime}\left(q_{2}^{e}\right)<U_{1}\left(x_{1}\right) \cdot V^{\prime}\left(q_{1}^{e}\right)=c_{1}{ }^{\prime}\left(q_{1} * *\right) \cdot x_{1}$ indicates that any quality standard below $q_{2}^{e}$ further reduces consumers' utility in jurisdiction 1 , government 1 would never reduce its quality standard below $q_{2}^{e}$ as long as its inhabitants have higher quality preferences than the inhabitants in jurisdiction 2. 
We can therefore always expect the quality standard of a high-quality jurisdiction to be somewhere between its efficient level and the level of the jurisdiction with the lowest quality preference. Let's now briefly compare this result with the result of Sinn's model. In the model presented here, there are only two jurisdictions, whereas in Sinn's model there is a large number of jurisdictions. Raising the number of jurisdictions would raise $\bar{x}$ too, since $\bar{x}$ is total consumption $\bar{X}$ in the common market as a share of the number $n$ of inhabitants of one jurisdiction $(\bar{x}=\bar{X} / n)$. A falling number $n$ of inhabitants per jurisdiction resulting from an increase in the number of jurisdictions would thus raise $\bar{x}$. However, it would not raise per capita consumption $x_{j}=X_{j} / n$ of one jurisdiction, since $X_{j}$ drops to exactly the same extent as $n$. Thus, the quality standard of any jurisdiction which is not the lowest-quality jurisdiction decreases as the number of inhabitants $n$ per jurisdiction decreases too. In figure 1 , the $\left[c^{\prime}\left(q_{1}^{* *}\right) \cdot \bar{x}\right]$-line turns to the left as $n$ decreases, thus leading to lower quality standards in equilibrium. However, any quality standard $q_{j}^{u} \neq q_{2}^{e}$ will always remain above the efficient quality standard $q_{2}^{e}$ of the lowest-quality jurisdiction, in our case jurisdiction 2 .

In the Sinn model, by contrast, the $\left[c^{\prime}\left(q_{1}^{* *}\right) \cdot \bar{x}\right]$-line even turns to a vertical line, which reduces the quality standard to its minimum value $q^{*}$. The reason is that Sinn implicitly allows for positive economic profits even in long-term equilibrium. If this were true, governments could trade higher profits resulting from reductions in quality standards and, hence, production costs against consumer utility. With a large number of very small jurisdictions, then, consumer utility would always be a weak argument compared to domestic profits since the number of domestic consumers who would enjoy (high) quality standards of domestic producers would be next to zero under these conditions. Any increase in profit would thus easily outweigh such a negligible effect of an increase in quality on a 
representative domestic consumer. However, allowing for positive economic profits does not seem reasonable as long as no barriers to entry into the respective market can be assumed. In quality competition among producers on the market, such barriers to entry are usually explained by sunk costs that arise when producers invest in high qualities but, during a period of reputation building, temporarily realize only the market prices of low qualities. ${ }^{5}$

When "high-quality prices" can only be realized after a period of reputation building, then the losses incurred during this period are sunk costs. Moreover, investment in advertisement or other expenses for the accumulation of reputation are to be viewed as sunk costs as well. These sunk costs, in turn, serve as a barrier to entry for competitors and, hence, allow for economic profits after a reputation has been built up and prices according to the high quality can be realized by the high-quality producer. However, these economic profits are an indication for a functioning quality competition on traditional markets. In this case no governmental quality regulation would be necessary and, according to Sinn's selection principle, no government would engage in any quality regulation. By contrast, when quality competition on markets fails then there would be no economic profits. Note that quality regulations by governments are no substitute since the reason for economic profits are barriers to entry generated by a process of reputation building by producers.

For these reasons, no economic profits are allowed in this model. Non-myopic governments will take this into account. Consequently, consumers' utility matters since even the smallest increase in consumers' utility cannot be outweighed by economic profits of domestic firms. It is true, though, that consumer's utility counts the more, the smaller is the number of jurisdictions in the common market.

\footnotetext{
${ }^{5}$ See Shapiro (1983), pp: 667 - 669; Ungern-Sternberg/Weizsäcker (1981): 614 - 615.
} 
However, for some other reasons the result of a quality standard below the efficient level $q_{1}^{u}$ but above the level $q_{2}^{e}$ of the lowest-quality jurisdiction may not be feasible under certain institutional conditions. This is so since, for any quality standard $q_{1} * *>q_{2}^{e}$, domestic producers will incur a loss. As long as there are no restrictions on policy instruments of the jurisdictions' governments, all except the lowest-quality government would pay a subsidy to domestic producers in order to compensate for this loss. The level of the subsidy would be calculated as follows. If consumers could detect quality differences they would be willing to pay a price according to the domestic quality standard. Since government 1 would choose a quality standard $q_{1}^{u}$, price would be $P\left(q_{1}^{u}\right)$. In long-term equilibrium, this price would just suffice to cover average costs, thus leaving zero economic profits. Since consumers cannot detect quality standards, the price in equilibrium would be competed to the lowest-quality level $P\left(q_{2}^{e}\right)=c_{2}$. Total loss incurred by domestic producers would be this price difference times domestic production $\pi \cdot \bar{X}$. The amount of subsidies would thus sum up to:

$$
\left.P\left(q_{1}^{u}\right)-c_{2}\right] \cdot \pi \cdot \bar{X}
$$

A welfare-maximizing government would pay a subsidy according to equation (21) if it could legally do so. In this way it would realize a quality standard $q_{1}^{u}$. However, in the European Union for example, decentralized governments are not allowed to subsidize domestic producers. Doing so would violate the EC contract. In this case all decentralized governments which are not the lowest-quality government will be forced to reduce their quality standards to the lowest-quality standard $q_{2}^{e}$ in order to prevent their producers from going bankrupt. Alternatively, they could keep their quality standard on the high level and accept that domestic production of the respective consumption good would collapse. Whether governments will lower quality standards or not cannot be decided without further criteria as 
long as there are zero economic profits. In any case, however, the quality standard of the lowest-quality jurisdiction $q_{2}^{e}$ will be established all over the common market when subsidies are prohibited.

To conclude, there are two possible outcomes of regulatory competition when consumers are perfectly ignorant with respect to different quality standards across jurisdictions:

- If subsidies are allowed, the equilibrium quality standard $q_{j}^{u}$ of all but the lowest-quality jurisdiction will be below its efficient level $q_{j}^{e}$ but above the lowest-quality level $q_{2}^{e}$. The higher the number of jurisdictions in a common market and, hence, the smaller the number $n$ of inhabitants in each jurisdiction, the closer will the equilibrium standard $q_{j}^{u}$ be to the lowest-quality level $q_{2}^{e}$.

- If subsidies are not allowed, the lowest-quality level $q_{2}^{e}$ will be established as a common standard all over the common market. There will be no higher standard than that. However, regulatory competition will not drive quality standards below $q_{2}^{e}$ and as low as $q^{*}$, as was suggested by Sinn.

Note that these somewhat more optimistic results still rest on the assumption that consumers are perfectly ignorant with respect to the different quality standards. In the next section, I will argue that this is not realistic, at least not under any circumstances. I will then briefly show that if consumers are unable to judge producer's quality but are nevertheless able to detect differences between governmental quality standards, regulatory competition will yield results that are even superior to harmonized quality standards based on average quality preferences in a common market. 


\section{Detectable Quality Standards}

Sinn rejects the case that consumers cannot detect producers' qualities but can distinguish between high and low quality standards. In his view this seems unrealistic. In my view, however, it seems even unrealistic to assume that the "degree of ignorance" in the case of producers' qualities would be identical with the degree of ignorance in the case of quality standards. It rather seems reasonable to assume that this degree differs. The reasons are as follows (see Apolte 1999, pp. 118-122):

- When it comes to producers' qualities consumers have to observe large numbers of different qualities supplied on the market. By contrast, the number of jurisdictions and, thus, quality standards will in most cases be much lower. Information costs will hence be lower in regulatory competition compared to usual quality competition via markets.

- Still more important perhaps is the fact that governments are principally obliged to make any quality standards available to the public. This implies an important difference from the point of view of the economics of information between market competition for producers' qualities and regulatory competition among governments. The difference is that governmental quality standards will principally be available ex ante, that is before any market transaction has been made. By contrast, producers' qualities will at best be available ex post, that is after the purchased good has already been consumed (so called "experience goods," see Nelson 1970). What is more, producers' qualities of the respective good can even ex post only be observed indirectly as long as producers are not obliged to make information about the relevant properties of the good available to the consumers. In some extreme cases, qualities cannot even be observed indirectly, for example in cases where harmful effects of consumption occur only sporadically (like airplane crashes, see Knorr 1997) or where utility derived from consumption cannot be 
judged by consumers, like in the case of pharmaceuticals (so called "credence qualities," see Darby/Karni 1973).

Especially the second argument seems to point in a direction of different degrees of ignorance since the central reason for a classic Akerlof-type lemon problem is that information on qualities is available to consumers only ex post. In case of regulatory competition, however, information on quality standards is principally available ex ante, although it may sometimes be costly for individual consumers to utilize this information. But different degrees of ignorance between producers' qualities on the one hand and quality standards on the other does not require perfect information on the latter. It only requires better information.

I would therefore suggest to distinguish between different cases which are all possible in reality. First, consumers could be well informed about both producers' qualities and governmental quality standards. Second, consumers could be equally badly informed about producers' qualities and governmental quality standards. This is the "Sinn case." Finally, producers' qualities could be more or less undetectable by consumers whereas governmental quality standards could be judged to a sufficient degree.

In the first case, quality competition would work on a pure market base. There would be no need for quality regulation by the governments. In the second case, quality competition on the market would fail and regulatory competition would lead to the results described in the last section. In the last case, however, quality competition on the market would certainly fail but regulatory competition would not. In the remainder of this section I would like to show that regulatory competition would even lead to superior results compared to harmonized quality standards. This would even be the case if the different quality preferences are not regionally distributed according to the borders of jurisdictions. To see this, assume once again two 
jurisdictions 1 and 2 with 1 being the high-quality jurisdiction. Assume further two groups of consumers $\mathrm{A}$ and $\mathrm{B}$ which sum up to the entire population of the two jurisdictions $2 \cdot n$. Finally, assume that group A consists of the "high-quality consumers." Consequently, group A will buy its entire consumer goods in jurisdiction 1 and group B will buy its goods entirely in jurisdiction 2 .

Note that members of group 1 are not necessarily identical with the population of either jurisdiction 1 or jurisdiction 2 . They could as well be scattered over the two jurisdictions. As a result, there will be trade among jurisdictions 1 and 2 . This trade will endogenously determine the market shares $\pi$ and $(1-\pi)$ of the producers in the two jurisdictions. The members of group A as a share of the total population of the common market will hence be identical with the market share $\pi$ of producers in jurisdiction 1 .

Each government will now maximize utility of a representative citizen by setting one quality standard valid for all producers in the respective jurisdiction. Jurisdiction 1 will remain as the high-quality jurisdiction as long as a change to a low quality standard does not increase utility of the average consumer in jurisdiction 1. Consumers, in turn, will not be able to observe producers' qualities but will be able to observe governmental quality standards. Their willingness to pay thus depends on quality standards. According to equation (13), government one's objective function would be:

$$
\begin{aligned}
& \max _{q_{1}^{* *}} ! U^{A}\left(\pi \cdot x_{1}\right) \cdot V^{A}\left(q_{1} * *\right)+U^{B}\left((1-\pi) \cdot x_{1}\right) \cdot V^{B}\left(q_{2} * *\right)+\bar{y}_{1}^{d}+P\left(q_{1} * *\right) \cdot \pi \cdot x_{2} \\
& -c\left(q_{1} * *\right) \cdot \pi \cdot \bar{x} .
\end{aligned}
$$

Since consumers can observe quality standards there will be no economic profits nor will there be losses from exports. This means that: 


$$
P\left(q_{1} * *\right) \cdot \pi \cdot x_{2}-c\left(q_{1} * *\right) \cdot \pi \cdot x_{2}=0 .
$$

Since $\bar{x}=x_{1}+x_{2}$, the last two terms of equation (22), that is $P\left(q_{1}^{* *}\right) \cdot \pi \cdot x_{2}-c_{1}\left(q_{1} * *\right) \cdot \pi \cdot \bar{x}$, reduce to $-c\left(q_{1}^{* *}\right) \cdot \pi \cdot x_{1}$. The objective function thus simplifies to:

$$
\max _{q_{1}^{* *}} ! U^{A}\left(\pi \cdot x_{1}\right) \cdot V^{A}\left(q_{1} * *\right)+U^{B}\left((1-\pi) \cdot x_{1}\right) \cdot V^{B}\left(q_{2} * *\right)+\bar{y}_{1}^{d}-c\left(q_{1} * *\right) \cdot \pi \cdot x_{1} \cdot
$$

The first-order condition with respect to the quality standard is:

$$
U^{A}\left(\pi \cdot x_{1}\right) \cdot V^{A}\left(q_{1} * *\right)=c^{\prime}\left(q_{1}^{* *}\right) \cdot \pi \cdot x_{1} .
$$

Correspondingly, the first-order condition of government 2 is:

$$
U^{B}\left((1-\pi) \cdot x_{2}\right) \cdot V^{A}\left(q_{2} * *\right)=c^{\prime}\left(q_{2} * *\right) \cdot(1-\pi) \cdot x_{2} .
$$

Conditions (25) and (26) are both equivalent with condition (18a) for an efficient quality standard. The differences in the quality standards $q_{1}^{* *}$ and $q_{2} * *$ correspond to the differences in the quality preferences of members of group A an B. There are no externalities involved here even though part of the high-quality production in jurisdiction 1 raises utility of consumers in jurisdiction 2. The reason is that prices correspond to quality. But what is more, the result of regulatory competition is superior to a harmonization of quality standards as long as there are differences in quality preferences. Differences in quality standards will then help to better match the different quality preferences, while a single harmonized standard would only match the quality preferences of the average consumer of the common market. 


\section{Conclusions}

In this paper I have critically examined an approach by Hans-Werner Sinn for examining regulatory competition among governments. Regulatory competition arises in a common market where two or more jurisdictions exist which independently set their respective quality standards and where mutual acceptance of quality standards is guaranteed. In this case import of goods cannot be rejected by any government for the reason that they have been produced under quality standards different from the quality standards of the respective importing jurisdiction. I have changed Sinn's assumptions in two ways: In section 3, I have given up his assumption of a large number of jurisdictions and assumed the limiting case of only two jurisdictions. In section 4, I have changed his assumption that consumers have an identical "degree of ignorance" with respect to voluntarily chosen producers' qualities on markets and to governmentally enforced quality standards.

It can be shown that when consumers have an identical degree of ignorance but when there is only a small number of large jurisdictions, the quality standard of the jurisdiction with higher quality preferences will, in regulatory competition, end up below its efficiency level but somewhere above the level of the lowest-quality jurisdiction. However, since any quality standard above the lowest standard in the common market will generate a loss for the producers in higher-quality jurisdictions, this result will only be feasible as long as governments can compensate for this loss via subsidies. If subsidies are not allowed, like in the European Union, then all quality standards will be driven down to the lowest standard in the common market.

They will not, however, be driven down further to the lowest possible level, as was the result in the model by Sinn. This will even hold when the number of jurisdictions is large. The 
reason is that, different from quality competition in usual markets, no barriers to entry will be built up in regulatory competition. Thus, no economic profits can survive. Taken together, the resulting quality standards will always be closer to their respective efficient levels than in the model by Sinn.

However, all except the lowest quality standard will certainly be inefficiently low. The extent to which quality standards in equilibrium depart from efficient levels depends on the degree of homogeneity in quality preferences in a common-market's population as well as on the number of jurisdictions competing for quality standards. Hence, there is always some degree of competition of laxity in regulatory competition as long as consumers are completely ignorant with respect to governmental quality standards. Whether or not such a result may be acceptable, however, will crucially depend on how further advantages of regulatory competition (see for example Siebert/Koop 1993; Woolcock 1994) are weighed against inefficiently low quality standards. In this respect it must not be forgotten that real-world governments usually do not act as welfare maximizers. Some beneficial effects can thus be expected from competition. In this view, the famous Cassis de Dijon decree and the henceforth accepted principle of mutual recognition of quality standards in the EU may well make sense, given the relatively few and relatively large jurisdictions in the EU and the comparatively high degree of homogeneity of the population across the EU member countries.

This somewhat more optimistic result will be further supported if we take into consideration that complete ignorance of consumers with respect to different governmental quality standards is but one possible case. I have tried to make clear that there may well be other relevant cases in which consumers may not be able to observe voluntarily chosen producers' qualities but may be able to observe governmentally enforced quality standards. In these cases, regulatory competition will even be superior to a harmonized standard since it allows 
for different quality standards according to differences in the quality preferences of the consumers. In reality, all cases will most probably be found, that is the case that consumers can judge producers' qualities as well as governmental quality standards, the case that consumers cannot judge producers' qualities but can judge governmental quality standards and, finally, the case that they can neither judge producers' qualities nor governmental quality standards. Public policy is bound to consider all these cases and act accordingly.

\section{References}

Akerlof, G. A., 1970. The market for "lemons": quality uncertainty and the market mechanism. Quarterly Journal of Economics 84, 488 - 500.

Apolte, Th., 1999. Die ökonomische Konstitution eines föderalen Systems. J. C. B. Mohr (Paul Siebeck), Tübingen.

Darby, R. R., Karni, E., 1973. Free competition and the optimal amount of fraud. Journal of Law and Economics 16, 67 - 88.

Flatters, F., Henderson, V., Mieszkowski, P., 1974. Public goods, efficiency, and regional fiscal equalization. Journal of Public Economics 3, 99 - 112.

Kihlstrom, R, Riordan, M., 1984. Advertising as a signal. Journal of Political Economy 92, $427-450$.

Knorr, A., 1997. Do "blacklists" enhance aviation safety? Intereconomics 32, 14 - 22.

Kreps, D. M., Wilson, R., 1982. Reputation and Imperfect Information. Journal of Economic Theory 27, $253-279$.

Leland, H. E., 1979. Quacks, lemons, and licensing: a theory of minimum quality standards. Journal of Political Economy 87, 1328 - 1346.

Nelson, P., 1970. Information and consumer behavior. Journal of Political Economy 78, 311 329.

Shapiro, C., 1983. Premiums for high quality products as returns to reputations. Quarterly Journal of Economics 97, 659 - 679.

Siebert, H, Koop, M., 1993. Institutional competition versus centralization: quo vadis Europe? Oxford Review of Economic Policy 9, 15 - 30.

Sinn, H.-W., 1997. The selection principle and market failure in systems competition. Journal of Public Economics 66, 247 - 274.

Spence, M., 1976. Informational aspects of market structure: an introduction. Quarterly Journal of Economics 90, 591 - 597.

Sun, J.-M., Pelkmans, J., 1995. Regulatory competition in the single market, in: Journal of Common Market Studies 33, 67 - 89.

Ungern-Sternberg, Th. R.., Weizsäcker, C. C., 1981. Marktstruktur und Marktverhalten bei Qualitätsunsicherheit. Zeitschrift für Wirtschafts- und Sozialwissenschaften 101, 609 621.

Wilson, C., 1980. The nature of equilibrium in markets with adverse selection. Bell Journal of Economics 11, 108 - 130.

Wolinsky, A., 1983. Prices as signals of product quality. Review of Economic Studies 50, 647 -658 . 
Woolcock, S., 1994. The Single European Market. Centralization or competition among national rules? Royal Institute of International Affairs, London.

Zodrow, G. R., Mieszkowski, P., 1986. Pigou, Tiebout, property taxation, and the underprovision of local public goods. Journal of Urban Economics 19, S. 356 - 370. 


\section{Jurisdictional Competition For Quality Standards:}

Competition of Laxity?

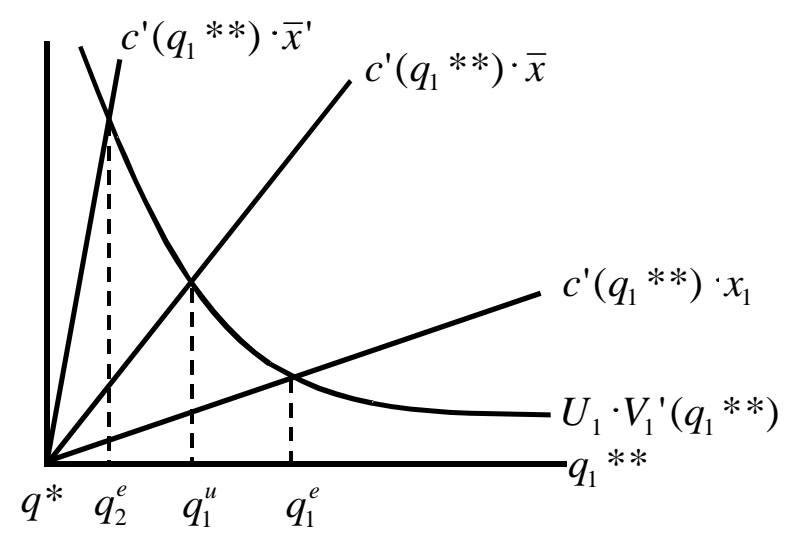

FigURE 1: SUBOPTIMAL QUALITY STANDARD IN REGULATORY COMPETITION 